\title{
Strategi Komunikasi Humas dalam Memperbaiki Citra Kementerian Pemuda dan Olahraga
}

\author{
https://doi.org/10.25008/caraka.v1i1.41 \\ MEILISSA ELVIANI \\ N.R NADYA KARINA \\ Universitas Paramadina, Indonesia
}

\begin{abstract}
The red-handed arrest of Youth and Sports Ministry officials by the Corruption Eradication Commission at the end of 2018 once again put the government institution on the spotlight. Corruption cases have always been under the spotlight particularly when they involve government institutions. The graft case involving officials of the Youth and Sports Ministry prompted its public relations service to adopt an appropriate strategy to prevent its image from deteriorating and instead to improve it. This research aims to see the strategy adopted by the ministry's public relations service to address a crisis of public confidence. This research uses a qualitative method by collecting data through documentation studies. Hopefully, this research will serve as a reference for other institutions that may face the same problem.
\end{abstract}

Keywords: Communication, image, confidence

\section{ABSTRAK}

Operasi tangkap tangan (OTT) Komisi Pemberantasan Korupsi terhadap pejabat Kemenpora tahun 2018 membuat lembaga pemerintah ini kembali menjadi sorotan masyarakat. Kasus korupsi selalu menjadi sorotan masyarakat terutama yang melibatkan lembaga pemerintah. Kasus ini membuat Kemenpora melalui humas harus membuat strategi yang tepat agar citra lembaga ini tidak semakin memburuk atau bahkan bisa diperbaiki. Penelitian ini bertujuan untuk mengetahui strategi yang digunakan humas Kemenpora dalam menghadapi krisis kepercayaan masyarakat. Penelitian ini menggunakan metode kualitatif dengan pengumpulan data melalui studi dokumentasi. Penelitian ini diharapkan menjadi acuan bagi lembaga lain yang mungkin mengalami situasi yang sama mengingat terdapat beberapa kasus serupa saat ini sehingga bukan tidak mungkin dimasa yang akan datang akan terjadi kasus serupa. Kata Kunci: Komunikasi, citra, kepercayaan

Kata kunci: Strategi komunikasi; citra; korupsi; krisis komunikasi; kemenpora

\begin{tabular}{|l|}
\hline Meilissa Elviani's email: Meilissa.elviani20@gmail.com \\
\hline N.R Nadya Karina's email: nadyakarina@windowslive.com \\
\hline Para penulis menyatakan tidak mempunyai konflik kepentingan dalam penelitian dan penerbitan publikasi ini. \\
\hline Copyright @ 2020 (Meilissa Evliani dan N.R Nadya Karina). \\
Licensed under the Creative Commons Attribution-NonCommercial-ShareAlike 4.0 (CC BY-SA 4.0) \\
Available at http://caraka.web.id \\
\hline Submitted: 19 April 2020, Revised: 10 May 2020, Accepted: 21 June 2020 \\
\hline
\end{tabular}




\section{PENDAHULUAN}

Kesuksesan prestasi Indonesia di ajang Asian Games maupun Asian Para Games 2018 tidak bisa dilepaskan dari peran Kementerian Pemuda dan Olahraga RI (Kemenpora). Pada pekan olahraga internasional itu, Indonesia sukses meraih posisi nomor empat dengan total perolehan medali 31 emas, 24 perak dan 43 perunggu. Jumlah perolehan medali ini merupakan yang terbanyak bagi kontingen Indonesia sepanjang sejarah keikutsertaan di ajang olahraga tingkat Asia.

Kesuksesan di ajang Asian Games kemudian diikuti pula oleh kesuksesan di Asian Para Games satu bulan kemudian. Indonesia bukan hanya sukses merebut posisi lima besar tetapi juga mencatatkan perolehan medali terbesar sepanjang sejarah dengan rincian 37 emas, 47 perak dan 51 perunggu.

Persiapan yang dilakukan dengan matang dalam jangka panjang termasuk pelaksanaan try out ke luar negeri ditambah dukungan supporter yang luar biasa menjadi faktor penentu suksesnya atlet-atlet Indonesia. Kemenpora sendiri sudah sejak awal tahun mencairkan anggaran bagi kebutuhan pemusatan latihan nasional (pelatnas) bagi para atlet, jauh lebih cepat dari tahun-tahun sebelumnya.

Namun segala pujian yang datang bertubi-tubi usai suksesnya prestasi atlet-atlet di ajang multi event tersebut, pada akhir tahun 2018 terjadi penangkapan tertuduh korupsi di Kemenpora. Komisi Pemberantasan Korupsi (KPK) melakukan operasi tangkap tangan (OTT) terhadap beberapa pejabat Kemenpora yang terlibat korupsi dana hibah KONI, lembaga yang secara struktural ada di bawah Deputi IV Kemenpora.

Jumlah uang yang disalahgunakan mencapai tujuh miliar rupiah. Kasus korupsi di Kemenpora itu bukanlah yang pertama kali terjadi. Para masa pemerintahan sebelumnya, pejabat kementerian itu juga terlibat korupsi bahkan sampai menterinya dihukum penjara.

Bagi sebuah instansi seperti kementerian, image atau citra sangatlah penting karena mencerminkan reputasi dan kehormatan diri (Hasan, 2010; Naryoso, 2016). Banyak hal dilakukan oleh Lembaga, kementerian atau perusahaan untuk mempertahankan citra positif yang dimilikinya. Bahkan ketika terjadi musibah yang menyebabkan rusaknya citra, maka dengan segera dilakukan berbagai upaya untuk memperbaiki citra. Dalam hal ini ilmu komunikasi tidak dapat dipisahkan dalam suatu organisasi (Mulyana, 2000; Fajar, 2009).

Oliver (2007: 50) mengatakan: "citra adalah suatu gambaran tentang mental ide yang dihasilkan oleh imaginasi atau kepribadian yang ditunjukan kepada publik oleh seseorang, organisasi dan sebagainnya".

Operasi Tangkap Tangan yang dilakukan oleh KPK di Kemenpora membuat citra kementerian itu tercoreng sehingga harus segera dilakukan upaya memperbaikinya, mengingat kasus seperti itu bukan hanya terjadi sekali.

Dalam konteks seperti itulah penelitian ini dilakukan dengan tujuan untuk melihat bagaimana strategi humas Kemenpora memperbaiki citranya setelah mengalami peristiwa OTT tersebut untuk kedua kalinya. Penanganan krisis dengan strategi yang tepat akan menjadi contoh bagaimana sebuah Institusi atau lembaga pemerintah dapat memulihkan kembali nama baik dan kepercayaan masyarakat.

\section{KERANGKA TEORI}

Divisi Hubungan Masyarakat (Humas) atau Public Relations merupakan bagian integral dalam suatu Lembaga swasta maupun pemerintah (Effendy, 2006; 2009). Tugas humas adalah menciptakan citra positif; memelihara kondisi agar suatu lembaga atau kementerian berada dalam situasi kondusif, beriklim kerja sehat, mempunyai hubungan sosial yang baik. 
Menurut Djanalis Djanaid sebagaimana dikutip oleh Kusumastuti (2002:22), ada dua fungsi public relations yaitu fungsi konstruktif dan fungsi korektif. Dalam fungsi konstruktif, public relations mendorong semua aktivitas atau kegiatan yang dilakukan perusahaan maupun organisasi sehingga aktivitasnya dapat terencana dan berkesinambungan dengan kecenderungan bersifat proaktif.

Sedangkan dalam fungsi korektif, public relations diibaratkan sebagai pemadam kebakaran. Apabila pada sebuah perusahaan atau organisasi terjadi masalah yang berkaitan dengan publik, maka persoalan itu harus segera diatasi dan diselesaikan. Dalam kaitan itu, peran humas sangat penting dalam mendukung performa organisasi baik di level internal maupun eksternal (Sanityastuti, 2009; Elvinaro, 2010; Colin, 2005; Rumanti, 2002).

Sementara itu, agar tujuan-tujuan komunikasi dapat tercapai secara efektif dan efisien, maka diperlukan suatu strategi yang tepat dari divisi humas (Rachmiatie, 2016; Hutagalung et al, 2018). Strategi pada hakikatnya adalah perencanaan (planning) dan manajemen (management) untuk mencapai tujuan. Untuk mencapai tujuan tersebut, strategi tidak berfungsi hanya sebagai peta petunjuk arah saja, melainkan juga harus menunjukkan bagaimana taktik operasionalnya.

Berbagai strategi dilakukan oleh Kemenpora dalam merespon terjadinya OTT KPK di kementerian itu. Strategi pertama yang dilakukan adalah menyampaikan pernyataan pers baik yang berasal dari menteri maupun pejabat yang berwenang serta dari divisi humas sebagai garda terdepan dalam penyampaian informasi.

Grand Theory yang digunakan dalam menentukan strategi tersebut adalah Theory of Image Restoration Strategies dari William Benoit (1995). Teori Restorasi Benoit pada prinsipnya menyangkut lima hal yaitu: (1) denial, suatu penolakan terhadap tuduhan yang dialamatkan pada lembaga yang mengalami krisis; (2) evading responsibility, yakni menolak tanggung jawab atau menyangkal telah melakukan suatu perbuatan; (3) reducing offensiveness, mengurangi persepsi negatif dengan menunjukkan berbagai ide positif di masa lalu; (4) corrective action, membuat janji dan mengambil langkah-langkah tertentu guna memperbaiki keadaan agar peristiwa serupa tidak terjadi lagi; (5) mortification yakni mengakui kesalahan, memohon maaf dan bertanggung jawab atas peristiwa yang terjadi.

Menurut Benoit, denial dapat dilakukan dengan menolak secara sederhana (simple denial) melalui ungkapan tidak mengakui perbuatan, atau dengan cara menyalahkan pihak lain (shifting the blane).

Pada Langkah evading responsibility, penyangkalan dilakukan dengan cara (1) menuduh ada kambing hitam (scapegoating) pada peristiwa tersebut; (2) mengakui terjadinya peristiwa namun hal itu terjadi karena kurangnya kontrol dan tanggung jawab petugas (desfeasibility); (3) menuduh para petugas tidak kompeten dan tidak memahami informasi dengan baik sehingga terjadi suatu peristiwa (ofensif). Ketiga Langkah menghindar dari tanggung jawab tersebut merupakan stategi menghindar dengan alasan peristiwa yang terjadi itu adalah musibah (an excuse on accident).

Pada langkah reducing offensiveness, ada dua strategi yang dapat diambil yakni bolstering, berupaya mengurangi dampak negatif dari benak khalayak dengan menyampaikan ide-ide atau ungkapan nilai-nilai positif pada masa lalu tanpa harus mengaitkannya dengan peristiwa sekarang. Cara lainnya adalah minimization, mengungi citra negatif dengan persuasi bahwa kejadian yang terjadi tidak seburuk yang disangkakan. Juga bisa menempuh cara perbandingan (differentiation), membandingkan dua perilaku kontradiktif untuk mengurangi perasaan negatif. Langkah lainnya menggunakan taktik menyerang (attacking accuser) atau langkah memberi kompensasi (compensation), memberi ganti rugi untuk menebus kesalahan. 


\section{METODOLOGI}

Penelitian ini menggunakan pendekatan kualitatif dengan metode deskriptif kualitatif. Peneliti mendeskripsikan atau mengkonstruksi wawancara mendalam terhadap subjek penelitian. Di sini peneliti bertindak sebagai fasilitator dan realitas dikonstruksi oleh subjek penelitian.

Metode deskriptif kualitatif menurut Moleong (2001) yaitu suatu penelitian yang mengasilkan data deskriptif berupa kata-kata lisan ataupun tertulis dari orang-orang atau pelaku yang diamati. Metode penelitian deskriptif kualitatif hanya memaparkan situasi atau peristiwa, tidak mencari dan menjelaskan hubungan, dan tidak menguji hipotesis atau membuat prediksi (Rahmat, 2009: 24; Kriyantono, 2009).

Sedangkan menurut Gunawan (2015) metode kualitatif berusaha memahami dan menafsirkan makna suatu peristiwa dan atau interaksi tingkah laku manusia dalam situasi tertentu menurut perspektif peneliti sendiri. Penelitian yang menggunakan penelitian kualitatif bertujuan untuk memahami obyek yang diteliti secara mendalam.

\section{HASIL PENELITIAN}

Berita kasus tangkap tangan oleh KPK terhadap beberapa pejabat Kemenpora terkait dengan dana hibah KONI dengan cepat menyebar dan menjadi berita utama di media massa. Selama berminggu-minggu topik itu menjadi pembicaraan sampai kasusnya berakhir di pengadilan dan pejabat yang terlibat mendapat hukuman penjara.

Akun media sosial kemenpora lantas dihujani berbagai komentar buruk tentang kasus tersebut. Mengingat kasus itu terjadi bersamaan dengan masa kampanye pemilihan Presiden, maka hal inipun dimanfaatkan oleh pendukung lawan politik presiden petahana untuk mendapatkan keuntungan dari peristiwa tersebut.

Humas Kemenpora segera merespon kejadian ini dengan menyiapkan langkah-langkah strategis guna mengantisipasi agar pemberitaan tidak menjadi bola liar. Merujuk pada bauran public relations, maka strategi yang dilakukan adalah melakukan penyebarluasan pesan secara cepat menggunakan berbagai saluran, terutama saluran media massa.

Berbagai strategi dilakukan oleh Kemenpora dalam merespon terjadinya OTT KPK di kementerian itu. Strategi pertama yang dilakukan adalah menyampaikan pernyataan pers baik yang berasal dari menteri maupun pejabat yang berwenang serta dari divisi humas sebagai garda terdepan dalam penyampaian informasi.

Sehari setelah peristiwa, Menpora didampingi Sekretaris Kementerian Pemuda dan Olahraga beserta pejabat jajaran esolon satu dan dua mengadakan jumpa pers. Hal ini sesuai dengan teori Edward L. Bernays (dalam Ruslan, 2001) tentang salah satu fungsi humas yaitu memberikan informasi yang kredibel kepada publik dalam waktu secepatnya.

Menpora dalam jumpa pers menyampaikan lima point penting, yaitu:

(1) "Saya atas nama Menpora dan Kementerian Pemuda dan Olahraga meminta maaf kepada seluruh rakyat Indonesia atas kejadian yang menimpa kantor Kementerian Pemuda dan Olahraga. Kami sangat prihatin, terkejut, dan kecewa terhadap kejadian yang menimpa Deputi IV Bidang Peningkatan Prestasi dan beberapa pejabat dan staf";

(2) "Kemenpora mendukung sepenuhnya langkah-langkah KPK dalam pemberantasan korupsi, karena semangat olahraga adalah semangat Sportif dan Fairness";

(3) "Mengingat keterkaitan dengan beberapa pejabat Kemenpora, kami tetap menunggu konfirmasi dari pihak KPK tentang penjelasan resmi dan konfirmasi lengkap tentang masalah tersebut";

(4) "Saya selaku Pimpinan Kemenpora selalu tidak henti-hentinya mengingatkan kepada 
seluruh jajaran Kemenpora untuk patuh secara prosedur terhadap semua ketentuan yang berlaku. Bahkan saat Rapim, saya minta kepada seluruh pejabat Kemenpora khususnya Eselon I dan II untuk menanda tangani pernyataan semacam pakta integritas yang di antaranya menekankan tentang kewajiban kepatuhan pada peraturan yang berlaku";

(5) "Kemenpora akan melanjutkan kerja seperti biasanya, melanjutkan apa yang sudah dicapai di beberapa tahun terakhir. Termasuk melakukan persiapan untuk Sea Games 2019 dan persiapan Olimpiade 2020. Dari hal ini kami belajar banyak, agar ke depannya lebih baik dalam menegakkan prinsip Good Governance, Sportivitas dan Fairness di Kemenpora".

Dari keterangan pers Menpora tersebut dapat dianalisis hal-hal berikut: (1) Menpora menyampaikan permohonan maaf kepada masyarakat atas kasus OTT tersebut. Langkah yang dilakukan Menpora tersebut sudah sesuai dengan langkah Mortification dari Benoit; (2) Kemenpora mendukung langkah-langkah yang diambil KPK dan menjanjikan ke depan kasus serupa tidak terjadi lagi. Hal ini masih sesuai dengan teori pemulihan citra Benoit yaitu corrective action.

Salah satu strategi yang diterapkan oleh humas kemenpora adalah dynamic strategy dengan melempar isu dan mengalihkan perhatian publik menjaga citra lembaga kemenpora. Sejak kasus OTT KPK, humas kemenpora melalui media sosial secara gencar memberitakan tentang prestasi-prestasi atlit Indonesia baik prestasi terkini maupun kilas balik prestasi masa lalu. Hal ini dilakukan untuk mengalihkan perhatian publik terhadap kasus ini.

Selain itu untuk menghindari komentar-komentar negatif warga nitizen, admin media sosial kemenpora memberlakukan kebijakan memblokir atau menghapus komentar tersebut. Pada hari dilaksanakannya sidang kasus ini, akun sosial media kemenpora lebih gencar mengulas dan menulis prestasi atlit-atlit maupun event olahraga yang sedang berlangsung saat itu.

Kemenpora juga tetap membuka diri terhadap kritik dan saran dari masyarakat dan terbuka terhadap pers dengan menyediakan akses luas serta menyediakan media center sebagai tempat bagi para wartawan.

Berdasarkan keterangan humas kemenpora, ternyata kasus operasi tangkap tangan KPK tidak berdampak significant terhadap pengikut akun media sosial kemenpora. Bahkan pertumbuhan follower media sosial instragram kemenpora justru mengalami peningkatan sebagaimana tersaji dalam data berikut ini.

Stategi yang dilakukan humas Kemenpora dapat dilihat dari kinerja media sosial instagramnya saat peristiwa itu terjadi. Dari enam postingan teratas akun resmi Kemenpora, setiap minggunya mendapatkan rata-rata jangkauan di atas 25.000 .

Pengikut akun itu juga meningkat sebanyak 32.500 orang dibanding tahun 2018. Adapun impressi pengunjung pada akun itu meningkat pada hari Rabu, Jumat, dan Sabtu saat ditayangkan konten-konten terkait milenial.

Follower akun resmi Instagram Kemenpora sebanyak 63 persen adalah lelaki dan 37 persen perempuan dengan rentang usia 18 - 24 tahun sebanyak 42\%; usia 25 - 34 tahun sebanyak 37\%; usia 13 - 17 tahun sebanyak 5\%; usia 25 - 34 tahun sebanyak $10 \%$, dan usia 45 - 65+ tahun sebanyak 6\% yang berasal dari seluruh wilayah Indonesia dengan dominasi pengunjung lebih banyak berasal dari Jakarta, Bandung, Yogya, Makassar, dan Bekasi.

Pengikut Instagram Kemenpora mencapai 297.812 orang dan telah memposting konten sebanyak 3.357 sebagai strategi untuk mengarahkan perhatian warga terhadap prestasi para atlet Indonesia baik di masa lalu maupun masa sekarang. 


\section{KESIMPULAN}

Kasus operasi tangkap tangan yang terjadi di Kemenpora menyebar secara cepat dan luas ke media dan menimbukan krisis komunikasi di kementerian itu. Strategi yang dilakukan Humas Kemenpora adalah melaksanakan penyebarluasan informasi baik melalui media massa konvensonal maupun melalui media sosial resmi milik Kemenpora.

Untuk mengatasi krisis kepercayaan yang terjadi dan untuk memperbaiki citra, kemenpora tidak melakukan strategi manajemen krisis secara khusus karena menganggap krisis yang terjadi tidak mempengaruhi kinerja. Namun kementerian itu menerapkan strategi komunikasi dalam menangani krisis yaitu mortification strategy, di mana kemenpora mengakui kalau terjadi krisis dan meminta maaf kepada masyarakat. Pilihan strategi tersebut sejalan dengan teori pemulihan citra dari Benoit. Strategi itu membawa hasil positif denan adanya anggapan dari masyarakat bahwa krisis yang terjadi adalah akibat dari kesalahan individu bukan kesalahan 43embaga kemenpora.

\section{REFERENSI}

Benoit, W. (1995). Accounts, Excuses, and Apologies: A Theory of Image Restoration Strategies. New York: State University of New York Press.

Colin, C. (2005). Pedoman Parktis untuk PR. Jakarta: Bumi Aksara.

Effendy, O.U. (2009). Human Relation \& Public Relations. Bandung: CV. Mandar Maju

Effendy, O.U. (2006). Hubungan Masyarakat: Suatu Studi Komunikasi. Bandung: Remaja Rosdakarya

Elvinaro, A. (2010). Metode Penelitian untuk Public Relations Kuantitatif dan Kualitatif. Bandung: Simbiosa Rekatama.

Fajar, M. (2009). Ilmu Komunikasi Teori dan Praktek.Yogyakarta: Graha Ilmu.

Gunawan, I. (2015). Metode Penelitian Kualitatif: Teori dan Praktik. Jakarta: Bumi Aksara

Hasan, E. (2010). Komunikasi Pemerintahan. Bandung: Rifka Aditama.

Hutagalung, I \& Ritonga, R. (2018). Pengaruh Iklim Komunikasi dan Komitmen Organisasi terhadap Kepuasan Kerja Pegawai Kecamatan XYZ Bekasi, Jurnal Kajian Komunikasi, $6(2), 72-84$.

Kusumastuti. F. (2002). Dasar Dasar Humas. Jakarta: Ghalia Indonesia

Kriyantono, R. (2009). Teknik Praktis Riset dan Komunikasi. Jakarta: Kencana

Mulyana, D. (2000). Ilmu Komunikasi Suatu Pengantar. Bandung: Remaja Rodaskarya

Moleong, L.J. (2001). Metodologi Penelitian Kualitatif. Bandung: Remaja Rosdakarya.

Naryoso, A. (2016). Model Public Relations untuk Pembangunan Reputasi Pendidikan Menengah sebagai Sekolah Rujukan Berprestasi Berpotensi, Jurnal Komunikasi Ikatan Sarjana Komunikasi Indonesia, 1(1), 12-24.

Oliver, S. (2007). Strategi Public Relations. Jakarta: Esensi Erlangga Group

Rachmiatie, A. (2016). Membangun Kecerdasan Informasi dalam Peneguhan Karakter Bangsa, Jurnal Komunikasi Ikatan Sarjana Komunikasi Indonesia, 1(2), 114-121.

Ruslan, R. (2001). Manajemen Humas \& Manajemen Komunikasi: Konsep dan Aplikasi. Jakarta: Rajawali Pers.

Rumanti, M.A. (2002). Dasar-dasar Public Relations Teori dan Praktik. Jakarta: Grafindo.

Sanityastuti, M.S. et al. (2009) Dasar-Dasar Public Relation, Yogyakarta: Sukses offset. 